\title{
MODELLING SMEs' BEHAVIORAL INTENTION TO ADOPT ISLAMIC CROWDFUNDING-SMALL AND MEDIUM ENTERPRISES (ICSMES) MODEL AS A SOURCE OF FINANCING IN MALAYSIA
}

\author{
Mohamed Asmy Bin Mohd Thas Thaker \\ International Islamic University Malaysia, Malaysia. Email: asmy@iium.edu.my
}

\begin{abstract}
The present study has proposed Islamic Crowdfunding-Small and Medium Enterprises (ICSMEs) model to assist SMEs in meeting their need to access external financial services in Malaysia. Upon the proposed model, this study examines the behavioural intention of SMEs to use ICSMEs model. The primary data are collected from the survey administered to SMEs in the Klang Valley $(\mathrm{n}=250)$ and the analysis is conducted using Partial Least Squares (SmartPLS). Furthermore, the model has been validated its acceptance in the field by adopting the Technology Acceptance Model (TAM). This study has revealed that both the perceived usefulness and perceived easy to use are found to have a positive impact on the behavioral intention of SMEs to use ICSMEs model, which later assist them to access to financial services in Malaysia. Furthermore, perceived easy to use has a positive relationship and direct effect with perceived usefulness of SMEs to use the ICSMEs model. The findings of this study can be used to develop a specific framework in which to examine other components of using the ICSMEs model's behavior and to plan appropriate intervention strategies to increase financial accessibility by SMEs.
\end{abstract}

Keywords: Islamic Crowdfunding-Small and Medium Enterprises Model (ICSMEs); Financial Accessibility; Malaysia.

JEL Classification: G1; L3; O14.

Received : October 08, 2018

Revised : October 22, 2018

Accepted : November 29, 2018 


\section{INTRODUCTION}

SMEs' role have been acknowledged in both developed and developing economies. According to Hailey (1991), the roles of SMEs can be measured in terms of: economic (income generation), social (poverty reduction) and political (wealth redistribution). For economic contribution, SMEs help towards to the employment creation, wealth creation, and increase of output, mobilization of local resources and adaptation of indigenous technologies. Meanwhile, the social benefits include a reduction of poverty, balanced development, provision of goods and services that appropriate to a local need, a seed bed for new initiatives, and redistribution of both income and opportunity in the community. The role of SMEs in political can be realised from the redistribution of wealth, opportunity and therefore power within the community.

It is noted that the contribution of SMEs also cover a wide range of areas and sectors with disproportionate number of total establishments in many countries. Statistics show that SMEs represent about more than 70 percent of the total SMEs establishments in the most world economies and contribute around 60 percent of total employment, including in Malaysia. The statistics from Economic Census of SMEs' Profile (2011) indicate that SMEs constitute 97.3 percent of Malaysia's total business establishment, employ about 52.7 percent of the total workforce and contribute 33.5 percent to the Gross Domestic Product (GDP). Majority of SMEs are in the services sector with 90.0 percent followed by manufacturing sector with 5.9 percent and 3.0 percent from construction sector.

Despite these recognized importance and its contribution towards the economy, a considerable number of empirical studies that investigate the problem of assessing external finance by SMEs in Malaysia exist (Thaker et al., 2013; Thaker et al., 2015; Hashim, 1999; Saleh \& Ndubisi, 2006; Abdullah \& Mannan, 2010; SME Annual Report, 2011/2012; SME Masterplan, 2012-2020; Aris, 2006). Those studies empirically have found that (i) inadequate collateral, (ii) insufficient legal status, (iii) high transaction costs, (iv) insufficient information and documentation, (v) no financial track record, (vi) nature and quality of business, (vii) rigidity of the financing procedure and (viii) lack of awareness on financial facility are among the prominent factors that hindered SMEs from accessing external finance. Furthermore, most of the financial institutions reluctant not to serve SMEs because the latter are perceived as high risks of default, high costs of transactions and perceived low relative profitability.

The Malaysian government has responded to particular issue by allocating a huge amount for financial assistance and providing various programmes, however, hitherto the effort is seen as ineffective when the impacts of business activities are found to be insignificant. Such situation occurs when the assistance program is offered through many government or private agencies without appropriate observation. Furthermore, Abdullah (1999) claimed that ineffectiveness of government assistance programs is due to: (i) limited number of SMEs receives full range of assistance, (ii) inefficient allocation of resources, and (iii) the programs focusing on developing only new enterprises. Therefore, in spite of the government efforts to promote accessing to finance through various measures, SMEs are continuously facing the problem of accessing finance. 
It can, therefore, be rightly asserted that the SMEs' financial accessibility requires other innovative financing mechanism and sources of funding in addition to the government funding. As such, a new mechanism that will allow for a sustainable source of financing is needed in assisting SMEs in Malaysia. In lieu with this, the present study proposed Islamic Crowdfunding-Small and Medium Enterprises (ICSMEs) Model. Islamic Crowdfunding-Small and Medium Enterprises (ICSMEs) Model is expected to be as a suitable model that can effectively address or minimize the constraint of financial accessibility by SMEs in Malaysia. Later, this study uses of the theory of Technology Acceptance Model (TAM) to justify the behavioral intention of SMEs to using the ICSMEs model. To the best knowledge of the researcher, there has been none of the research investigate empirically the optimatisation of Islamic-based crowdfunding as a source of financing for SMEs using TAM.

Accordingly, the main objective of this paper is to propose ICSMEs model and test the behavioural intention of SMEs to use ICSMEs model as source of financing their business. The remaining part of this paper is therefore organised as follows: the second section presents literature review. Section three presents the methodology applied in this study. Section five presents the main results of the study and its discussion. Section six provides the conclusion and policy recommendations.

\section{LITERATURE REVIEW}

\subsection{SMEs Financial Challenges}

Several studies stated that Malaysian SMEs face the problem of accessing finance (Hashim, 1999; Saleh \& Ndubisi, 2006; Abdullah \& Mannan, 2010; SME Annual Report, 2011/2012; SME Masterplan, 2012-2020). Many of SMEs find difficulties in accessing external financing since they are perceived as a high-risk and a high cost-service market segment (Duc et al., 2008; Vos et al., 2007). In addition, the requirement of collateral, high cost of financing, difficulty in providing business information, business transaction records and business plans are among the factors that prevent them from accessing financing (Aris, 2006).

In the case of external debt financing particularly from the financial institutions, the financial institutions typically request collateral in order to mitigate the risks associated with the moral hazard. However, the lack of collateral is probably the most widely cited obstacle encountered by SMEs in accessing finance including in Malaysia. For financial institutions, the majority of the SMEs do not have acceptable collateral that can make them qualify for a loan. In Malaysia, the study conducted by Thaker (2015), Thaker et al. (2016), Aris (2006) and Meza (2012) revealed that an absence of adequate collateral and strict collateral requirement prevented SMEs to obtain loan from the financial institutions. In 2005, almost 56 percent of SMEs in Malaysia exposed to the difficulties to access external finance due to the lack of collateral (Aris, 2006).

Lack of accessing external finance by micro enterprises also occurs because of insufficiency of information and documents to support the loan application (Census of Establishment and Enterprise, 2005). Information related to the business such as size, age and type of ownership are needed by the financial 
institutions before approving any application of the loan. As SMEs are often on the stage of start-up and opening new plant, most of them probably do not have enough information and documents to support their loan application. Hence, due to an absence of insufficient information and documents, the financial institutions are reluctant to provide financing to them. The statistics provided by Census of Establishment and Enterprise (2005), indicated that more than 13 percent of the SMEs in Malaysia constrained from accessing external finance due to insufficient information and documents to support loan application.

Furthermore, one of the key requirements in credit evaluation by financial institutions is financial track record behavior of customer. However, in the context of SMEs in Malaysia, they are having difficulty in getting loan from the financial institutions because they are not able to provide financial track record (Aris, 2006; Hassan et al., 2010). As most of SMEs are involved at the early stage of businesses and start-up businesses, they cannot provide any financial track record history. Such scenario leads SMEs to be considered as risky business. Thus, the financial institutions are reluctant to provide loan facility for them. According to the statistics released by Census of Establishment and Enterprise in 2005, almost 11 percent of SMEs in Malaysia unable to access external finance due to the failure of providing financial track record.

The nature and quality of business of SMEs are also become obstacles for them to access loan from financial institutions in Malaysia (Census of Establishment and Enterprise, 2005; SME Annual Report, 2008). As SMEs are considered as a risky business, the financial institution in Malaysia assumed that the nature of their businesses do not meet the basic standards for receiving any serious consideration for financing. It is also complicated with the quality of business plan that are submitted for financing, which is often fall below minimum standards. Based on the statistics provided by the Census of Establishment and Enterprise (2005), more than five percent of SMEs in Malaysia unable to obtain financing because of their nature and quality of businesses.

Numerous studies have pointed out that high cost of external financing particularly interest rate is a reason of why SMEs in Malaysia reluctant to access external finance from financial institutions (Saleh et al., 2005; SME Annual Report, 2011/2012). Usually, the financial institutions charge higher interest rates particularly for SMEs in order to compensate the higher costs of information collection, the smaller volume of external financing and the greater risk of failure. Furthermore, due to the absence of appropriate collateral by SMEs, many of the financial institutions therefore respond to this situation by imposing high interest rate in the credit market. The financial institution and micro finance institutions in Malaysia offer loans to SMEs at high interest rates. For example, commercial banks such as Agro Bank Malaysia, Maybank Malaysia, Public Bank Malaysia and SME Bank of Malaysia offer micro financing scheme at the rate range from 5 percent to 8 percent, while micro finance institutions such as Amanah Ikhtiar Malaysia (AIM) offered financing at 10 percent. The recent survey which was held in second quarter of 2012, indicated that about 33 percent of SMEs in Malaysia are facing the problem of accessing finance due to the high cost of external financing (SME Annual Report, 2011/2012). 
According to the study by Hassan et al. (2010), SMEs in Malaysia are unable to access external financing due to excessive rigid procedures imposed by the financial institutions and government agencies. For example, the financial institutions tend to scrutinise different aspects of SMEs when making the lending decision, with the first step in the loan approval often involving the banks attempting to seek more details from borrowers. Later, it is followed with several documentation processes which involving lending terms and conditions, and long-time processing of loan (Braveman \& Guasch, 1986). On the other hand, the government agencies that provides financial assistance for SMEs also practising bureaucracies, red-tapes and favouritism. Due to the rigidity of financing procedure, SMEs use their source of financing merely from internal sources.

\subsection{Technology Acceptance Model (TAM)}

The Technology Acceptance Model (TAM) is pioneered by Davis (1989) and received empirical support for being robust in predicting technology adoption in various contexts of technologies (McKinnon and Igonor, 2008; Park, 2009). TAM theorizes that an individual's behavioral intention to adopt a technological system or innovation is influenced by two beliefs, perceived usefulness and perceived ease of use. Use of the TAM is predicated on individuals having control over whether or not they use the system (Pearlson and Saunders, 2006).

Perceived Usefulness (PU) is defined as "the degree to which an individual believes that using a particular system would enhance his or her productivity" (Davis, 1989). Meanwhile, Perceived Ease of Use (PEOU) is defined as "the degree an individual believes that using a particular system would be free of effort" (Davis, 1989).

The previous empirical studies have applied TAM in respective industries namely educational sector, SME's, general public and the manufacturing environment. For example, Ndubisi et al. (2001) tested the applicability of TAM for predicting entrepreneurs' technology usage and found it to be valid. Ma'ruf et al. (2002) further validated the usefulness of TAM in predicting Internet shopping whereas Ramayah et al. (2002) tested the applicability of TAM for Internet banking users and non-users. In the education sector Ramayah et al. (2003a) tested the TAM incorporating motivational variables to explain Internet usage among students of institutions of higher learning. Ramayah and Aafaqi (2004) expanded the use of TAM in predicting e-library usage with the aid of selfefficacy. On the other hand, Ramayah and Jantan (2003) used the TAM to explain Internet shopping among the Malaysian public.

The technology acceptance model (TAM) is used in this study for its predictive ability in studies involving SMEs to engage in technology adoption. The causal relationships between perceived usefulness (PU), perceived ease of use (PEOU) and behavioural intention to use (BIU) Islamic Crowdfunding-Small and Medium Enterprises (ICSMEs) Model are specified in the TAM to reflect the new environment of the proposed model (see Figure 1). 


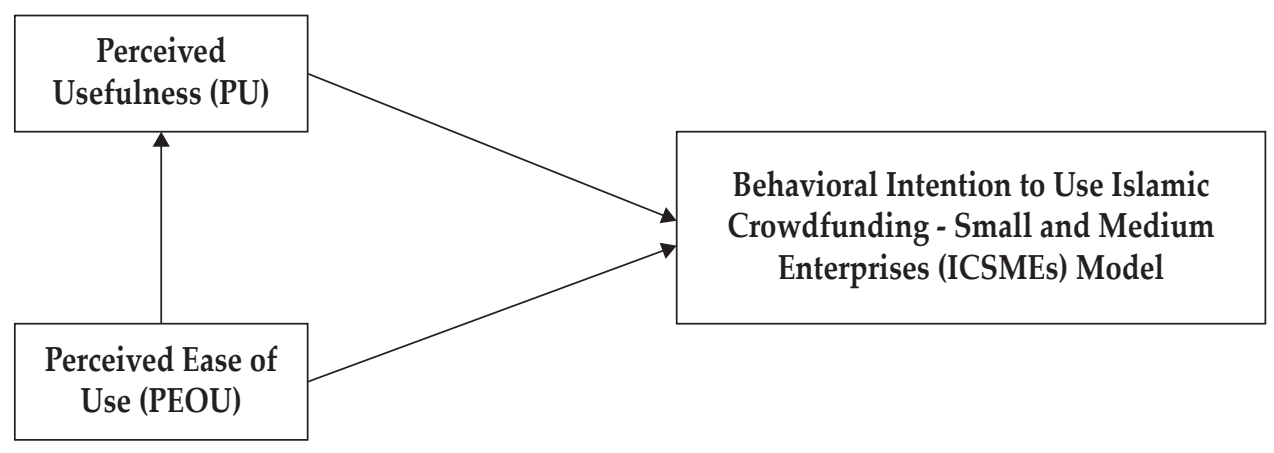

Figure 1.Technology Acceptance Model (TAM)

Based on TAM framework, the present study comes out with three main hypotheses, which are:

(i) Hypothesis 1

Ho: There is no significant (positive) influence of perceived usefulness on the intention to engage in ICSMEs model among SMEs.

Ha: There is a significant (positive) influence of perceived usefulness on the intention to engage in ICSMEs model among SMEs.

(ii) Hypothesis 2

Ho: There is no significant (positive) influence of perceived ease of use on the intention to engage in ICSMEs model among SMEs.

Ha: There is a significant (positive) influence of perceived ease of use on the intention to engage in ICSMEs model among SMEs.

(iii) Hypothesis 3

Ho: There is no significant (positive) influence of perceived ease of use on perceived usefulness of ICSMEs model among SMEs.

Ha: There is a significant (positive) influence of perceived ease of use on perceived usefulness of ICSMEs model among SMEs.

\subsection{Crowdfunding}

In a few years crowdfunding has become a widespread and effective alternative for raising capital to support investment opportunity and source of venture capital. The crowdfunding market has grown tremendously in recent years. An industry report (Massolution, 2013) indicates that around $\$ 5.1$ billion total transactions occurred globally in 2013 (rising from \$2.6 billion in 2012), while a recent World Bank Report (2013) expects that the crowdfunding market to skyrocket and reach about $\$ 93$ billion in 2025 in developing countries alone. Such a growing market has garnered the attention of policy makers, which have legalized crowdfunding in many countries such as United States, United Kingdom, Finland, Australia, France, India, Brazil and Italy (The World Bank, 2013; Massolution, 2013).

Crowdfunding or crowd financing is "the collective effort of individuals who engage in network and pool their money, usually via the Internet, to support efforts initiated by other people or organizations" (Ordanini et al., 2011). Crowdfunding 
comes to practise with the help of web-based platform (i.e. RocketHub, Kickstarter, and IndieGoGo) and explosive growth of social media, with Facebook and Twitter at the forefront, as well as the affordable online payment transfer services such as Paypal and MoneyGram. The scope of crowdfunding projects is very diverse such as for business start-up, development projects, development and catastrophe aid, scientific research, entertainment such as video games, movies and music, political campaigns, utilities and many other targets.

Massolution (2013) defines four categories of crowdfunding platforms (CFPs) namely equity-based, lending-based, donation-based, and reward-based crowdfunding. In equity-based crowdfunding, funders receive compensation in the form of fundraiser's equity-based or revenue, or profit-share arrangements. Whereas in lending-based crowdfunding, funders receive fixed periodic income and expect repayment of the original principal investment. In donation-based crowdfunding, funders donate to causes that they want to support, with no expected compensation. Finally, in reward-based crowdfunding, the primary objective of funders is to gain a non-financial reward. Thus, equity-based and lending-based crowdfunding considered as crowdfunding for financial return, while donation-based and reward-based crowdfunding are used for campaigns that appeal to funders' personal beliefs and passions. However, the present research focuses on the donation-based and reward-based crowdfunding due to its popularity, flexibility and compatibility with the objective of SMEs in Malaysia.

Since crowdfunding have been used widely in other countries to funds various philanthropic projects, entrepreneurial projects and charity purpose through small contribution from many sources, its application towards SMEs' development may have significant contribution to socio-economic development, in particular. Hence, this study will therefore help in creating more awareness about crowdfunding among potential SMEs and crowd funders that are willing to involve with Islamic Crowdfunding-Small and Medium Enterprises (ICSMEs) Model. This could therefore open an opportunity for another means of raising sustainable funds for SMEs.

\section{DEVELOPING ISLAMIC CROWDFUNDING-SMALL AND MEDIUM ENTERPRISES (ICSMEs) MODEL}

Our developed model which is known as Islamic Crowdfunding-Small and Medium Enterprises (ICSMEs) Model involves two main different parties which are SMEs and Crowd funders. SMEs are consisting of existing or new enterprises. Meanwhile, crowd funders are consists of the public or a large audience (the socalled "crowd"), where each individual provides a fund. Since the present study focuses on Islamic crowdfunding, the nature of crowdfunding will be based on Sadaqah-based crowdfunding (Donation-based crowdfunding), Hibah-based crowdfunding (reward-based crowdfunding), Murabahah-based crowdfunding (peer-to-peer crowdfunding), and Mudharabah-based crowdfunding (equity-based crowdfunding). The proposed model could be illustrated by Figure 2. 


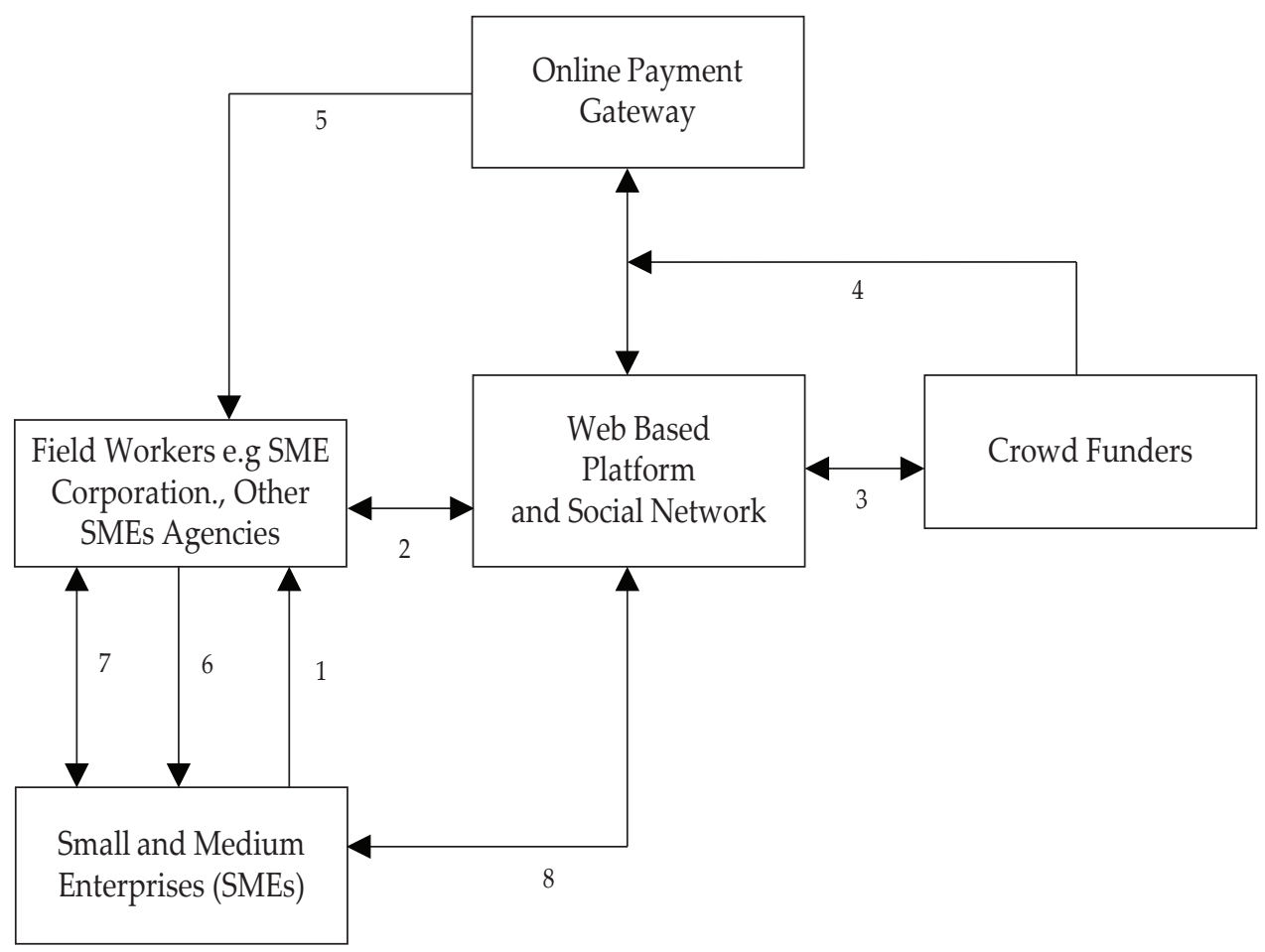

Figure 2. Islamic Crowdfunding-Small and Medium Enterprises (ICSMEs) Model

The following are the detailed explanation of Islamic Crowdfunding-Small and Medium Enterprises (ICSMEs) Model:

1. SMEs request for funding to field workers by submitting business proposal/ projects. The field workers in Malaysia can be consisting of SME Corporation and other SMEs related agencies. These field workers know their potential SMEs and do all the screening process to get funding from crowd funders.

2. Field workers submit SMEs proposals to the system or so called "Web Based Platform". Field workers can have their own "Web Based Platform" or outsourcing from third party. The field workers collect entrepreneur stories, business proposal, pictures, financing details, and uploads them to the system. The proposal/projects have to be funded within a predefined timeframe.

3. Crowd funders choose SMEs that they want to support based on their information uploaded into the system. Crowd funders browse the web to search financing requests and finally choose the SMEs they are willing to help by providing capital or fund. Crowd funders can choose either to involve in Sadaqah-based crowdfunding (Donation-based crowdfunding), Hibah-based crowdfunding (reward-based crowdfunding), Murabahah-based crowdfunding (peer-to-peer crowdfunding), and Mudharabah-based crowdfunding (equitybased crowdfunding).

4. Crowd funders transfer/send funds through online payment gateways. Filed workers can have their own payment gateways through collaboration with existing financial institutions. 
5. After receiving funding from crowd funders, the system will update the status of SMEs and keep track of received fund until it is ready to be distributed.

6. The system distributes the fund through field workers. Once the required fund is accumulated, the system will distribute the funds and notify corresponding field workers to get ready managing and supervising the SMEs. Field workers distribute the loans and update the status of loans through the system.

7. Field workers manage and monitor SMEs. Field workers must trace the progress and regularly updates the system with stories, pictures, or anything that shows the progress of SMEs. Field workers update SMEs' progress to the system. This will ensure transparency between the SMEs and the crowd funders.

8. The system communicates with SMEs for control and audit purposes through a simple communication media such as Short Message Services (SMS)

\section{RESULT AND FINDING}

\subsection{Data Collection, Sample, Data Analysis}

This study focuses SMEs in the area of Klang Valley (Selangor and Kuala Lumpur). This area is chosen as the database for SMEs, recorded the highest number. A self-administered survey was used to collect the data. A purposive sampling was drawn for the survey. The researchers opted for purposive sampling, as the participants were selected based on their willingness to provide information by virtue of their knowledge. Purposive sampling involved the identification and selection of SMEs (existing SMEs) that were proficient and well-exposed to the concept of crowdfunding. For the sample size, this study used Yamane's (1967) formula. This formula is given below:

$$
n=\frac{N}{1+N(e)^{2}}
$$

where:

$n$ = desired sample size

$\mathrm{N}=$ the population size

e $\quad=$ level of precision or sampling error (sampling error in this study is 5 percent)

By applying the formula, the total desired sample size or $\mathrm{n}$ became 400 . It was calculated based on a 95 per cent confidence level and a 5 per cent error level (Table I). Around $400 \mathrm{SMEs}$ were sent the questionnaire. In total, 280 questionnaires were returned, of which 250 were usable for data analysis purposes. The collected data was analysed using SmartPLS version 3.2.7. The choice of SmartPLS was made on the basis of its ability to measure causal relationships among all latent construct simultaneously, while dealing with measurement errors in the structural model (Farooq, 2016; Hair et al., 2017). The advantages of PLS include minimal restrictions on measurement scales, sample size and residual distributions (Chin et al., 2003). 


\subsection{Descriptive Analysis}

As depicted in Table 1, 66.1 percent of the respondents are male while 33.9 percent are female. It is apparent that the dominance of male respondents explains the role of male in pursuing economic activity than females. It follows the traditional division of labor which is gender-based, with the wife responsible for the family and the husband being the breadwinner and head of household (Higgins et al., 1994 \& Muhammad, 2012). This finding is relatively consistent with Malaysia's business environment where male business owners dominate compared to females even though the latter number is also increasing (Manan et al., 2011).

Almost three-quarters (72.1 percent) of the respondents are between the age group of 20-40, few are over 40 years of age (27.9 percent). Consequently, the responses expressed in the survey well reflect the attitudes and perceptions of the middle-aged and younger respondents (that is if we consider those above 40 to be the older respondents). This also reflects that majority of the respondents fall within active working population (Abbas et al., 2012). This group of population is actively involved in operating businesses to search for an income and to uplift their standard of living. Almost 67 percent of the respondents are married. Thus, it seemed that the findings of the survey would be highly influenced by the married middle-aged respondents. The results also indicate that majority of the participants that engage with business are married and it shows that married participants are actively involved in doing business to fulfil the responsibility towards their family members.

Besides, in terms of educational level, majority of respondents are well educated, with almost 29 percent holding a college diploma or matriculation and about 27 percent holding at least a bachelor degree or above. This information reflects the tendency of an educated generation to be involved in businesses. On the other hand, 44.4 percent of the remaining respondents completed primary or secondary school. A possible reason for them to start their own business at such a lower level of education is due to difficulties to find job with reasonable pay considering their present qualifications.

Table 1.

Distribution of Respondents by Gender, Age, and Marital Status

\begin{tabular}{lcc}
\hline Category & Items & Percent \\
\hline Gender & Male & 66.1 \\
Age Group & Female & 33.9 \\
& $20-30$ & 37.2 \\
& $31-40$ & 34.9 \\
Marital Status & $41-50$ & 17.2 \\
& Above 50 & 10.7 \\
Educational Level & Single & 29.2 \\
& Married & 66.8 \\
& Divorced & 4 \\
& Primary/Secondary School & 44.4 \\
& College Diploma/Matriculation & 28.7 \\
& Bachelor & 20.7 \\
\hline
\end{tabular}


According to Kharusi (2003), the age of enterprises can be grouped into three categories where group " $0-5$ " years can be classed as young firms, while the bands "6-10" and "11-15" years can be considered as middle aged, and "16 and over" as older firms. The results presented in Table 2 show that the majority of the respondents (63.3 percent) have been operating their business for $0-5$ years. Thus, from the findings of the current study, it is clear that most of SMEs are in their early stages of business, and can be classed as young firms.

On the other hand, about 25.2 percent of the respondents had been in business between 6 to 10 years. The findings reflect that these groups of SMEs are in the middle stage of business. Furthermore, 11.5 percent of the respondent indicates that they had been in business for more than 10 years and are considered as older firm. In terms of sectors, majority of the respondents (96.5 percent) are engaged in the services sector followed by agricultural sector ( 2 percent) as shown in Table 5. The remaining ( 1 percent) and ( 0.5 percent) are in manufacturing and construction sectors, respectively. This finding is consistent with the overall profile of small and medium-sized businesses in Malaysia. The services sector accounted for the bulk of the total share of 87 percent in total SMEs. By component-based SMEs, SMEs constitute the largest proportion in the services sector with significant involvement in the area of businesses such as retail, restaurant, wholesale, transportation and communication, and professional services (SME Annual Report 2011-2012). In addition, the rapid growth of services sector in Malaysia is also influenced by the strong domestic demand and several government initiatives to boost services sector.

Table 2.

Distribution of Respondents by Business Characteristics

\begin{tabular}{lcc}
\hline Category & Items & Percent \\
\hline No of Years in Business & $0-5$ Years & 63.3 \\
& 6-10 Years & 25.2 \\
& $>10$ Years & 11.5 \\
Sector & Services & 96.5 \\
& Agriculture & 2 \\
& Manufacturing & 1 \\
& Construction & 0.5 \\
\hline
\end{tabular}

\subsection{Assessment of Measurement Model}

The convergent validity was tested at the initial stage. During the test of convergent validity, indicator or items loadings, Average Variance Extracted (AVE) and Composite Reliability (CR) were taken into the consideration. Based on the results presented in Table 3, items' loading exceeded 0.6 for items, which meet the recommended value suggested by Hair et al. (2009). In terms of AVE threshold or requirement, Hair et al. (2006) suggested that AVE should exceed 0.5. In the current study, AVEs were in the range of 0.619 and 0.797 . The CR value ranged from 0.957 to 0.969 , which meet the recommended value of 0.7 suggested by Hair et al. (2006). Table 3 shows the results of measurement model. 
Table 3.

Results of Measurement Model

\begin{tabular}{|c|c|c|c|c|}
\hline Variables & Items & Loadings & AVE & CR \\
\hline \multirow[t]{9}{*}{ Perceived Usefulness (PU) } & PU1 & 0.902 & 0.717 & 0.958 \\
\hline & PU2 & 0.868 & & \\
\hline & PU3 & 0.881 & & \\
\hline & PU4 & 0.873 & & \\
\hline & PU5 & 0.876 & & \\
\hline & PU6 & 0.866 & & \\
\hline & PU7 & 0.842 & & \\
\hline & PU8 & 0.849 & & \\
\hline & PU9 & 0.628 & & \\
\hline \multirow[t]{12}{*}{ Perceived Ease of Use (PEOU) } & PEU10 & 0.811 & 0.619 & 0.957 \\
\hline & PEU11 & 0.821 & & \\
\hline & PEU12 & 0.848 & & \\
\hline & PEU13 & 0.822 & & \\
\hline & PEU14 & 0.727 & & \\
\hline & PEU15 & 0.77 & & \\
\hline & PEU16 & 0.838 & & \\
\hline & PEU17 & 0.847 & & \\
\hline & PEU18 & 0.795 & & \\
\hline & PEU19 & 0.796 & & \\
\hline & PEU20 & 0.809 & & \\
\hline & PEU21 & 0.794 & & \\
\hline \multirow[t]{7}{*}{ Behavioral Intention (BI) } & BI22 & 0.893 & 0.797 & 0.969 \\
\hline & $\mathrm{BI} 23$ & 0.916 & & \\
\hline & BI24 & 0.897 & & \\
\hline & BI25 & 0.898 & & \\
\hline & BI26 & 0.898 & & \\
\hline & BI27 & 0.881 & & \\
\hline & $\mathrm{BI} 28$ & 0.879 & & \\
\hline
\end{tabular}

After conducting earlier test of convergent validity, next, the discriminant validity needs to be tested. Previously, Fornell-Larcker (1981) criterion has been used to test discriminat validity. However, there has been a criticism on Fornell-Larcker (1981) criterion where, it is not reliably detect the lack of discriminant validity in common research situations (Henseler et al., 2015). Thus, Henseler et al., (2015) have suggested an alternative approach to access discriminant validity using heterotrait-monotrait ratio of correlations. Henseler et al. (2015) also went on to demonstrate the superior performance of this method by means of a Monte Carlo simulation study. As such we have also tested the discriminant validity using this new suggested method and the results are shown in Table 4. If the HTMT value is greater than $\mathrm{HTMT}_{0.85}$ value of 0.85 (Kline, 2011), or $\mathrm{HTMT}_{0.90}$ value of 0.90 (Gold et al., 2001) then there is a problem of discriminant validity. As all the values passed the $\mathrm{HTMT}_{0.90}$ (Gold et al., 2001) and also the $\mathrm{HTMT}_{0.85}(\mathrm{Kline}, 2011)$ as shown in Table 4, indicating that discriminant validity has been ascertained. Based on these results, it indicates that measurement model has adequate convergent validity and discriminant validity. 
Table 4.

HTMT Criterion

\begin{tabular}{lccc}
\hline Variables & BI & PEOU & PU \\
\hline BI & & & \\
PEOU & 0.881 & & \\
PU & 0.838 & 0.849 & \\
\hline
\end{tabular}

\subsection{Assessment of Structural Model}

Ramayah et al. (2016) have suggested using $\mathrm{R}^{2}$ to observe the goodness of the structural model. According to Hair et al. (2011), coefficient of determination and the level of significance of the path coefficients (beta values) can be captured by $\mathrm{R}^{2}$. The $\mathrm{R}^{2}$ for the current research is 0.76 , suggesting that 76 percent of the variance of behavioral intention of using ICSMEs can be explained by perceived ease of use and perceived usefulness.

Subsequently, in order to assess the statistical significance of path coefficients, the current study has calculated the path coefficients of the structural model and performed bootstrap analysis (re-sampling $=500$ ) (please see Table 5). Based on results, it revealed that perceived usefulness and perceived easy to use has a positive relationship with behavioral intention to use ICSMEs model with $\mathrm{b}=0.583, \mathrm{p}<0.05$ and $\mathrm{b}=0.329, \mathrm{p}<0.01$, respectively. In addition, perceived easy to use has a positive relationship and direct effect with perceived usefulness with $\mathrm{b}=0.81$ and significant at $\mathrm{p}<0.05$. Thus, $\mathrm{H} 1, \mathrm{H} 2$, and $\mathrm{H} 3$ are supported. Table 5 shows the results of Structural Model.

Table 5.

The Results of Structural Model

\begin{tabular}{lccccc}
\hline Hypothesis & R/ship & Std. Beta & Std. error & t-value & Decision \\
\hline H1 & PEOU $>$ BI & 0.583 & 0.072 & 8.053 & Supported \\
H2 & PU -> BI & 0.329 & 0.08 & 4.142 & Supported \\
H3 & PEOU -> PU & 0.81 & 0.028 & 29.003 & Supported \\
\hline
\end{tabular}

\subsection{Importance-Performance Map Analysis (IPMA)}

Ringle and Sarstedt (2016) stated that the IPMA's goal is to identify predecessors which have a relatively low performance but high importance for the target constructs. IPMA becomes a very useful analytical tool in PLS-SEM. IPMA graphically extends the standard path coefficient estimates in more practical way (Ringle and Sarstedt, 2016).

In this study, the behavioral intention of adopting ICSMEs is a target construct, which is predicted by two predecessors (perceived ease of use and perceived usefulness); refer to Figure 1. This study has performed IPMA and results is presented in Figure 3. The IPMA reveals that the construct PEOU has high performance and also an important variable in the prediction of behavioral intention of adopting ICSMEs. Meanwhile, PU already has high in performance but low importance compared than PEOU. 


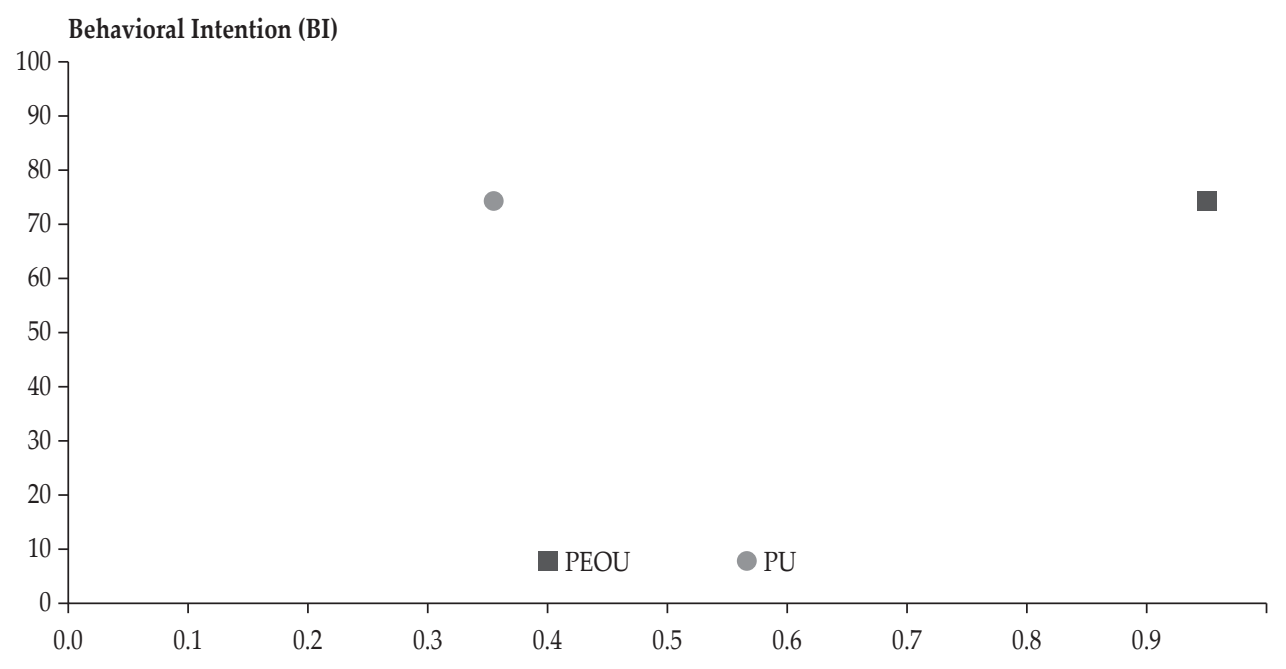

Figure 3. Importance-Performance Map Analysis

Table 6.

Importance-Performance Map Analysis Statistics

\begin{tabular}{lcc}
\hline Variables & Importance (Total Effect) & Performance (Index Values) \\
\hline PEOU & 0.95 & 75.514 \\
PU & 0.36 & 74.483 \\
\hline
\end{tabular}

\subsection{Discussion of Results}

In this study, the behavioural intention of SMEs to use Islamic Crowdfunding-Small and Medium Enterprises (ICSMEs) model was found to depend on perceived usefulness and perceived easy to use. Perceived usefulness is the perception that a given a technological-based system, it will help a user (in our case SMEs) to achieve his or her work goals. SMEs need a mechanism that could help them to raise financing to support their businesses. Thus, by using ICSMEs model which is through online platform, it will help SMEs to raise fund for start-up or expanding their business in Malaysia. This finding is consistent with Venkatesh et al. (2000), Abassi et al. (2011), and Cheng et al. (2006). This model is expected to create a positive perception towards SMEs, who are looking for external source of funding in Malaysia.

On the other hand, perceived ease of use is defined as the degree to which a person believes that easy-to-use technology was associated with greater intent to use it (Davis, 1989). Thus, the easier to involve with ICSMEs model, it will attract more Malaysian SMEs to raise fund using this platform. This finding is also similar to Davis (1989), Gefen et al. (2004) and Yi et al.(2003). Meanwhile, perceived ease of use was positively associated with perceived usefulness. It means that the easier the system was to use, the more useful it was perceived to be. Thus, ICSMEs model may need to have the features that useful to the user particularly SMEs, who are looking for external fund. 


\section{CONCLUSION}

This paper has developed Islamic Crowdfunding-Small and Medium Enterprises (ICSMEs) model. The model is expected to assist SMEs to meet their financing need for business expansion or start-up in Malaysia. Later, this study has empirically tested the behavioural intention of SMEs in adopting this model by applying TAM. The author has extended the application of TAM in the context of Islamic crowdfunding and SMEs. This study has proven that both perceived usefulness and perceived ease of use are directly significant in influencing the SMEs' intention to use ICSMEs model. The findings of this study can be used to develop a specific framework in which to examine other components of using ICSMEs' behavior and to plan appropriate intervention strategies to increase its capacity in boosting SMEs' development in Malaysia.

\section{REFERENCES}

Abbasi, M.S., Chandio, F.H., Soomro, A.F., \& Shah, F. (2011). Social Influence, Voluntrariness, Experience and The Internet Acceptance: An Extension of Technology Acceptance Model with a South-Asian Country Context. Journal of Enterprise Information Management, 24(1), 30-52.

Abdullah, M. A., \& Manan S. K. A. (2010). Adequacy of Financial Facilities for Small-Medium Business: Empirical Findings from Malaysia. International Review of Business Research Papers, 6(4), 535-548.

Abdullah, M.A. (1999). Small and Medium Enterprises in Malaysia: Policy Issues and Challenges. Ashgate, England.

Aris N.M. (2006). SMEs: Building Blocks for Economic Growth. Paper Presented at National Statistics Conference, Department of Statistics, Malaysia 4-5 September.

Braverman, A., \& Guasch, J. L. (1986). Rural Credit Markets and Institutions in Developing Countries: Lesson for Analysis from Practice and Modern Theory. World development, 14(10-11), 1253-1267.

Census of Establishments and Enterprises. (2011). Department of Statistics. Malaysia, Putrajaya.

Cheng, T., Lam, D.Y.C., \& Yeung, A.C.L. (2006). Adoption of Internet Banking: An empirical Study in Hong Kong. Decision Support Systems. 42(3), 1558-1572.

Chin, W. W., Marcolin, B. L., \& Newsted, P. R. (2003). A Partial Least Squares Latent Variable Modeling Approach for Measuring Interaction Effects: Results from a Monte Carlo Simulation Study and an Electronic-Mail Emotion / Adoption Study. Information Systems Research, 14(2), 189-217.

Davis, F. D. (1989). Perceived Usefulness, Perceived Ease of Use, and User Acceptance of Information Technology. MIS Quarterly, 13, 983-1003.

Farooq, M. S., \& Radovic-Markovic, M. (2016, October). Modeling Entrepreneurial Education and Entrepreneurial skills as Antecedents of Intention Towards Entrepreneurial Behaviour in SIngle Mothers: a PLS-SEM approach. Paper Presented at the Fifth International Conference "Employment, Education and Entrepreneurship" (EEE 2016), Faculty of Business Economics and Entrepreneurship, University of Belgrade, Belgrade, 198-216. 
Fornell, C., \& Larcker, D. F. (1981). Structural Equation Models with Unobservable Variables and Measurement Error: Algebra and Statistics. Journal of Marketing Research, 382-388.

Gefen, D. and Straub, D.W. (2004). Consumer Trust in B2C E-Commerce and The Importance of Social Presence: Experiments in E-Products and E-Services. Omega, 32, 407-24.

Gold, A.H., Malhotra, A., \& Segars, A.H. (2001). Knowledge Management: An Organizational Capabilities Perspective. Journal of Management Information Systems, 18(1), 185-214.

Hailey, J. (1991). Small Business Development in the Developing World: An Overview of Contemporary Issues in Enterprise Development. Cranfield Institute of Technology, Cranfield.

Hair et al. (2006). Multivariate Data Analysis (6th ed.). Prentice Hall, Upper Saddle River.

Hair, J., Hollingsworth, C. L., Randolph, A. B., \& Chong, A. Y. L. (2017). An Updated and Expanded Assessment of PLS-SEM in Information Systems Research. Industrial Management \& Data Systems, 117(3), 442-458.

Hair, J.F., Ringle, C.M., \& Sarstedt, M. (2011). PLS-SEM: indeed a silver bullet. J. Marketing Theory Pract. 19 (2), 139-152.

Hashim, M.K. (1999). A Review of The Role Of SMEs In The Manufacturing Sector In Malaysia. Malaysian Management Journal. Jun, 40-49.

Hassan et al. (2010). Financial Constraints \& Opportunities of Micro Enterprise Entrepreneur: A Theoretical Framework. Paper Presented at International Conference on Business And Economics Research Kuala Lumpur, 2010.

Kline, R.B. (2011). Principles and Practice of Structural Equation Modeling. New York, Guilford Press.

Massolution. (2013). 2013CF- Crowdfunding Industry Report.

McKinnon, K., \& Igonor, A. (2008). Explaining eLearning Perceptions Using the Technology Acceptance Model and the Theory of Planned Behavior. In E-Learn: World Conference on E-Learning in Corporate, Government, Healthcare, and Higher Education (pp. 2994-2999). Association for the Advancement of Computing in Education (AACE).

Meza V.S. (2012). Microfinancing Access Constraints in Both Malaysia and Costa Rica: Case of The Microenteprises Sector. Paper Presented at International Conference On Social Sciences \& Humanities 2012, Kuala Lumpur Malaysia.

Ndubisi, N. O., Jantan, M., \& Richardson, S. (2001). Is The Technology Acceptance Model Valid for Entrepreneurs? Model Testing and Examining Usage Determinants. Asian Academy of Management Journal, 6(2), 31-54.

Ordanini, A., Miceli, L., Pizzetti, M., \& Parasuraman, A. (2011). Crowd-funding: Transforming Customers Into Investors Through Innovative Service Platforms. Journal of Service Management, 22(4), 443-470.

Park, S. Y. (2009). An Analysis of The Technology ACceptance Model in Understanding University Students' Behavioral Intention to USe E-Learning. Journal of Educational Technology \& Society, 12(3), 150.

Ramayah, T., \& Aafaqi, B. (2004). Role of Self-Efficacy in E-Library Usage Among Students of a Public University in Malaysia. Malaysian Journal of Library $\mathcal{E}$ Information Science, 9(1), 39-57. 
Ramayah, T., Jantan, M., Mohd Noor, M. N., Razak, R. C., \& Koay, P. L. (2003). Receptiveness of Internet Banking by Malaysian Consumers: The Case of Penang. Asian Academy of Management Journal, 8(2), 1-29.

Ramayah, T., Ling, N. S., Taghizadeh, S. K., \& Rahman, S. A. (2016). Factors Influencing SMEs Website Continuance Intention in Malaysia. Telematics and Informatics, 33(1), 150-164.

Ramayah, T., Ma'ruf, J. J., Jantan, M., \& Osman, M. (2002). Technology Acceptance Model: Is It Applicable to Users and Non-Users of Internet Banking. In the Proceedings of The International Seminar, Indonesia-Malaysia, The Role of Harmonization of Economics and Business Discipline in Global Competitiveess, Banda Aceh, Indonesia (pp. 14-15).

Saleh A. S., \& Ndubisi, N.O. (2006). An Evaluation of SME Development in Malaysia. International Review of Business Research Papers, 2 (1), 1-14.

Saleh, A.S., Caputi P., \& Harvey C. (2005). Perceptions of Business Challenges Facing Malaysian SMES: Some Preliminary Results. Paper Presented at $5^{\text {th }}$ SMEs in a Global Economy Conference, August $2^{\text {nd }}-3^{\text {rd }}$, Senshu University, Kandajimbocho, Tokyo, Japan.

SME Annual Report. (2008). Rising to Meet Global Challenges. Kuala Lumpur, Malaysia.

SME Annual Report. (2011/2012). Redefining the Future. Kuala Lumpur, Malaysia.

SME Annual Report. (2012/2013). Embracing Changes. Kuala Lumpur, Malaysia.

SME Masterplan. (2012 -2020). Catalysing Growth and Income. National SME Development Council, Kuala Lumpur, Malaysia.

Thaker, M.A.M.T. (2015). The Problems Faced By Malaysian Micro Enterprises in Accessing External Finance: An Empirical Study. Paper Presented at International Symposium on Business and Management - Fall Session 2015, 8 September-10 September 2015. Kyoto, Japan.

Thaker, M.A.M.T., Mohammed, M.O., Duasa, J., \& Abdullah, M.A. (2016). Measuring The Factors That Determine Micro Enterprises' Intention To Use Integrated Cash Waqf Micro Enterprise Investment (ICWME-I) Model As A Source Of Financing. Gadjah Mada International Journal of Business, 18(2).

The World Bank. (2013). Crowdfunding's Potential for The Developing World. Washington, DC: World Bank.

Venkatesh, V., \& Davis, F.D. (2000). A Theoretical Extension of The Technology Acceptance Model: Four Longitudinal Field Studies. Manage. Sci. 46 (2), 186204.

Venkatesh, V., \& Morris, M.G. (2000). Why Don't Men Ever Stop To Ask For Directions? Gender, Social Influence, and Their Role an Technology Acceptance and Usage Behavior. MIS Quarterly, 24, 115-139.

Yi, M.Y., \& Hwang, Y. (2003). Predicting The Use of Web-Based Information Systems: Self-Efficacy, Enjoyment, Learning Goal Orientation, and The Technology Acceptance Model. International Journal of Human-Computer Studies, 59(4), 431-449. 
This page is intentionally left blank 